\title{
Controlling Lava Flow in Hawaii: Abilities and Perspectives
}

\author{
Anuar Kulmagambetov and Alexandru Gaina \\ Company Laitingen Financial Inc, Moscow 127410, Russia
}

\begin{abstract}
An analysis of the ground condition on Hawaii Island (Big Island) and relief of the southeastern flank indicates its instability and the danger of a large-scale landslide which could cause significant damages to the entire West Coast of the US. This article discusses the factors contributing to the occurrence of a landslide, as well as a method that makes it possible to significantly reduce the probability of it. This method makes it possible to control the lava flow by shaping the landscape of the island, or by directing the lava flow straight into the ocean.
\end{abstract}

Key words: Hawaii Kilauea, sustainable environment, volcanoes, landslide, lava diversion.

\section{Introduction}

The recent volcanic eruption in Hawaii and resulting fires and destructions thereof, once again raise the question of how to prevent the hazardous consequences of uncontrolled lava flows and their exposure on peoples' lives and on the entire island as a whole. What are the main issues? Let us consider major of them:

(1) Uncontrolled hot lava flows across the surface, which burn land, constructed premises, emit suffocating gases, taking together cause great damage and pose a serious threat to the favorable for life environment on the island.

(2) Uncontrolled movement of magma to the Earth's surface, which causes volcanic eruptions, lava flows, uncontrolled increase in the island size, and destruction of its individual parts.

(3) Uncontrolled landslides.

(4) Periodic earthquakes of varying intensity.

There are no tools available to influence earthquakes. We are able only to adapt to them, i.e. change building technologies and create the corresponding infrastructure. Nevertheless, the impact of the first three factors can

Corresponding author: Anuar Kulmagambetov, Ph.D., individual researcher, research fields: mathematics, engineering and artificial intelligence, email: anuar52@gmail.com. be mitigated. Therefore, these will be discussed.

\section{Hawaii, Landslides}

The growth of the islands of the entire Hawaiian archipelago is associated with volcanic activity, constant movement of the islands, and the fact that the islands are not monolithic rocks, but a complex structure formed by cooled lava, with numerous cracks and voids, as well as its own faults and dykes that can also move and break. Fig. 1 shows the volcanoes on Hawaii Island with faults and cracks.

Volcanic eruptions are associated with the movement of a hot magma flow to the Earth's surface. The rising magma has high pressure and temperature. This phenomenon leads to magma penetration into all possible faults and cracks in the soil, which causes them to heat up, melt, and expand. The magma mixed with water from underground sources, significantly increases the internal gas pressure that escapes to the surface ahead of magma through every crack, in the form of superheated steam. The volcano together with the caldera starts to "breathe"; the ground surface level rises and falls, fumarole gases are occasionally released.

High magma pressure causes volcanoes to erupt, old cracks to re-emerge and new cracks to appear, through 




Fig. 1 Map showing the five volcanoes that form the Island of Hawaii, rift zones and major subaerial structures of Mauna Loa and Kilauea Volcanoes, and the area covered by this map.

SWRZ, southwest rift zone of Kilauea Volcano; ERZ, east rift zone of Kilauea Volcano; MLNERZ, northeast rift zone of Mauna Loa Volcano; MLSWRZ southwest rift zone of Mauna Loa Volcano [1].

which the magma escapes to the surface. The magma rise softens and weakens the soil, thus creating preconditions for new landslides and rock falls. In the process of growth and destruction of volcanic cones, the configuration of the craters and calderas changes, part of the slope "flows" down, thus forming a new slope and a new terrain. These changes are proportional to the volume of lava released, the value of the magma's internal pressure in the crater, and the duration of the eruption itself. After each new eruption, a new layer of hardened lava is deposited on the surface of the island. The weight of the accumulated lava, as well as the soil weakening can cause part of the island to fall along the edge of cracks and faults into the ocean. Fig. 2 shows lava flows that have been running out from the Pu'u 'O'o volcano since 1983 [2]. The eruption that occurred in 2018 covers these and even larger areas to the east of the Middle East Rift Zone, with a large amount of lava released.

From previous geological surveys, it follows that over time, if nothing is done, catastrophic events will occur - powerful landslides and collapsing of various parts of the island, as they have repeatedly occurred on the islands throughout time [3]. During the entire history of the Hawaiian archipelago's formation, 68 large landslides are known, ranging in length from 20 


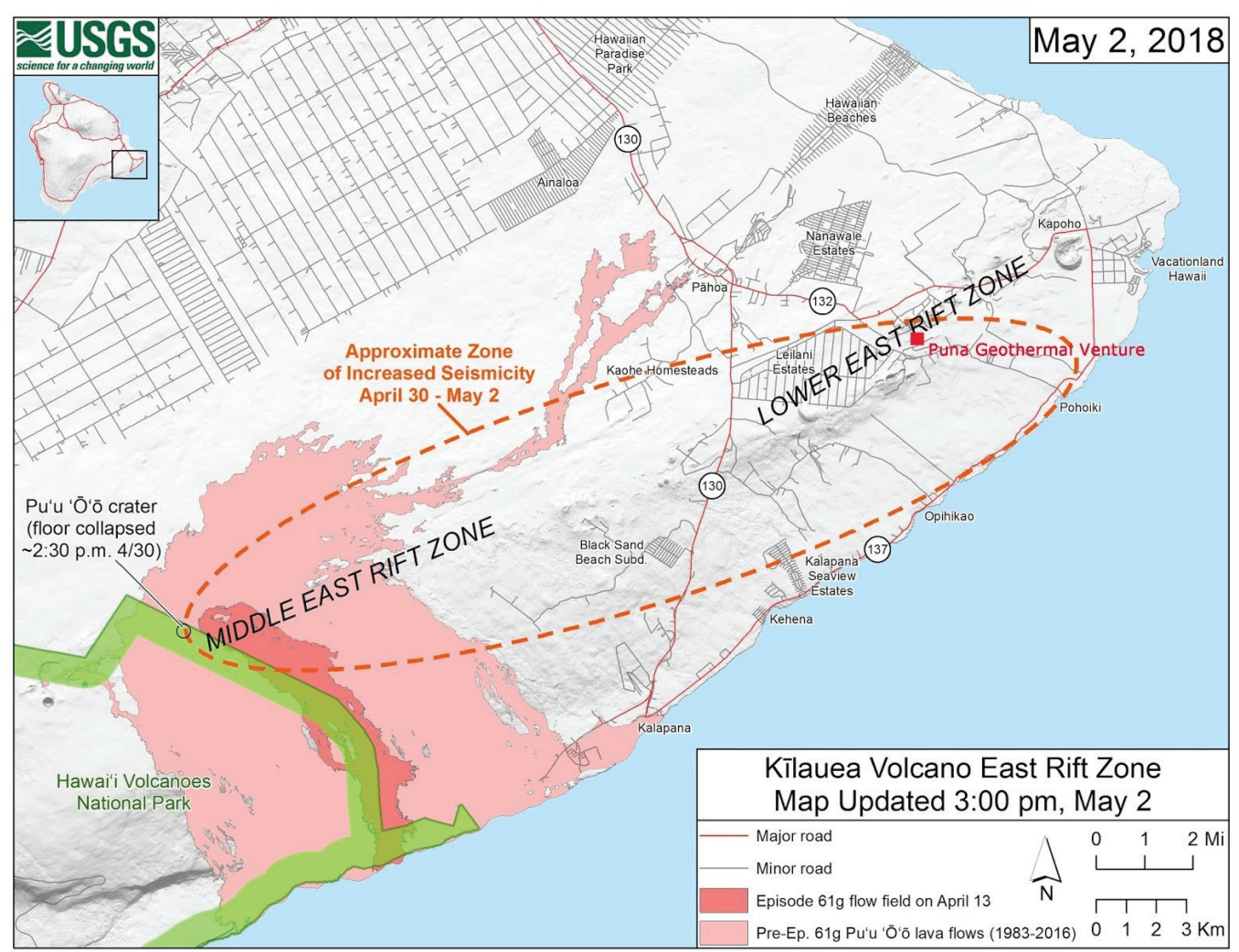

Fig. 2 Map showing the lava flows erupted from 1983 to present activity of Pu'u 'O'O and Kupaianaha.

to $300 \mathrm{~km}$ [4]. A huge landslide simultaneously covers both above and underwater parts, since the island represents only the top of the mountain, the greater part of which is hidden under the water. The summit of the Hawaii Island to its highest point, has an elevation of approximately $4.2 \mathrm{~km}$, and its base is about $6 \mathrm{~km}$ below sea level [2]. With each eruption, the numbers of cracks and gravity of the island's soil increase, along with the probability of collapses.

The most important additional factor in determining the occurrence of a giant landslide is the condition of the volcano rock massif itself-the structure of the volcano soil and the external geometry of the volcano slopes themselves. Apart from volcanic activity impacts, the base of the island is also continuously exposed to the effects of interaction with seawater, leading to qualitative changes in the mineral composition of the soil. The upper surface layers in the underwater part of the island (levels I and S, see Fig. 3) consist of hyaloclastites and deeper smectites, which are characterized by their lower density and reduced compressive strength (less than at level $\mathrm{P}$ by 3-4 times) [4]. This data was obtained as a result of drilling works conducted on the eastern slope of the island (Hawaii Scientific Drilling Project-HSDP). The lithological column of HSDP is shown in Fig. 3.

Seawater significantly affects the physical and chemical properties of glass fragments of cooled lava, reducing their strength and increasing their porosity, which is a serious forewarning of a significant landslide itself. In addition, the depth of the weakened layer of this part of the island is about $1,000 \mathrm{~m}$, confirming the raised concerns!

Looking at the overall picture, all evidence points to the imminent risk of the occurrence of a giant landslide. The layer of hyaloclastites can play the role of a skating rink. It facilitates the entire upper layer of the above-water part of the island together with its extensive underwater part, up to $1.5-2.5 \mathrm{~km}$ depth (hyaloclastites and smectites), to slide down the volcano 


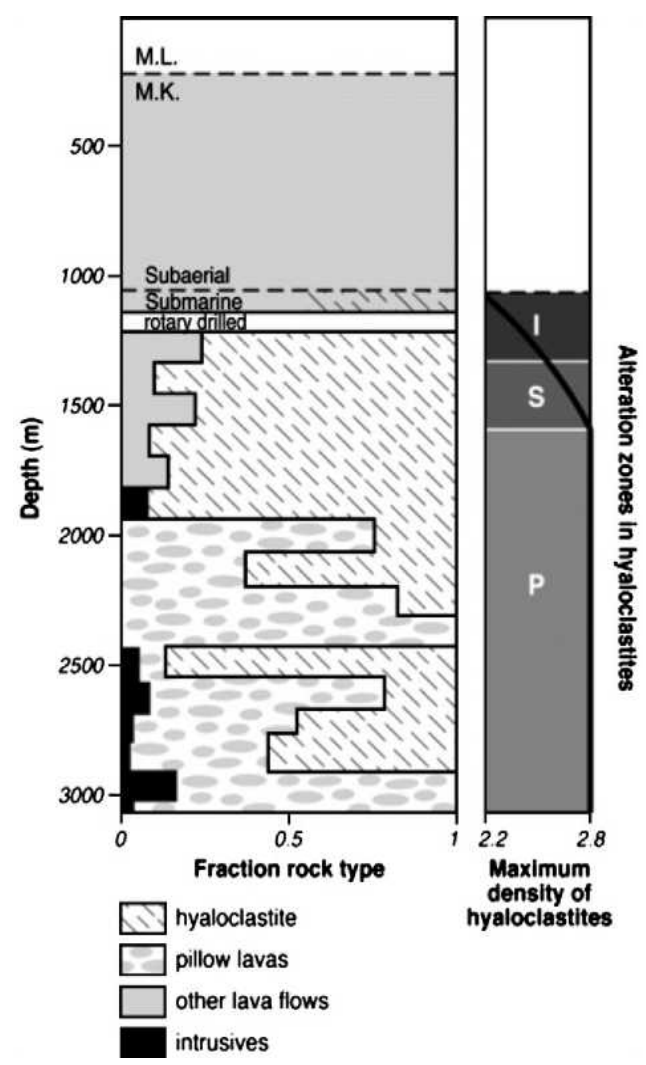

Fig. 3 Generalizedlithologic column of the HSDP corewith relative proportions of lithologies present.

M.L.-Mauna Loa, M.K.-Mauna Kea, I-incipient, $\mathrm{S}$ - smectitic, $\mathrm{P}$ - palagonitic. Densities shown on $\mathrm{g} / \mathrm{cm}^{3}$ [4].

slope. Due to reduced friction and deformation forces, the weak layers will set the horizontal layers of the soil in motion, which accelerate as they move and drag ever larger volumes of soil with them.

Surface rupture on the island can take place both along the fault line and along the cracks (there are many possibilities), and the landslide estimated volume will depend on this. One of the most dangerous areas is the Hilina fault zone. Landslides are and will always occur on the island! Large landslides by their nature are the most serious due to their potentially harmful effects. Let us consider an example.

Fig. 4 shows two possible scenarios of landslides. The first is minimal, where the flank "slips down", covering the area up to the upper boundary of the "New Bench" (drawn by a thin line). This major landslide can occur without significant consequences for the island; with a rapidly decaying wave amplitude and short wavelength. The second is the large flank collapse, covering the entire area titled "UNSTABLELAND". This landslide can have significant consequences depending on the size of the zone of weakness (area of instability). In the zone of the expected landslide in the Hilina fault system, this area of instability can exceed $2,100 \mathrm{~km}^{2}$ (see Fig. 1) [5], which is dangerous. There might be a third, catastrophic scenario, where the whole southeastern flank of the island collapses and breaks off along the fault line including the Kilauea volcano (Fig. 1). These scenarios are conditional and largely depend on the magnitude and duration of an earthquake. However, the estimated volume of the possible landslide will vary between $10,000-12,000 \mathrm{~km}^{3}[5]^{*}$. This is a huge volume and amount of energy! Even one-thousandth of this volume represents a serious threat, as the landslide triggers a powerful tsunami with a long wavelength capable of covering a distance of thousands of miles.

We have every reason to assume this scenario. Fig. 5 shows the sudden shift of the whole southeastern part of the island towards the ocean in early May 2018, while the island itself is constantly moving in the opposite direction! And these types of motion will continue.

\section{Natural Lava Tubes}

All volcanoes involved in an eruption and the locations of magma outflow are connected by means of a common internal magma reservoir where the lava tubes are spontaneously formed; see Fig. 6 [2], which shows a natural lava tube $12 \mathrm{~km}$ in length.

Magma rising to the surface through the mantle plume breaks out to the surface through the craters of existing volcanoes. Thus, the last eruption in Hawaii began with the Pu'u 'O'o volcano (Fig. 6). And as the pressure increased, the magma gushed out through the cracks, expanding them, and ascended the Kilauea

\footnotetext{
* The article contains a detailed analysis of the bathymetry of the entire Hilina Slump zone.
} 


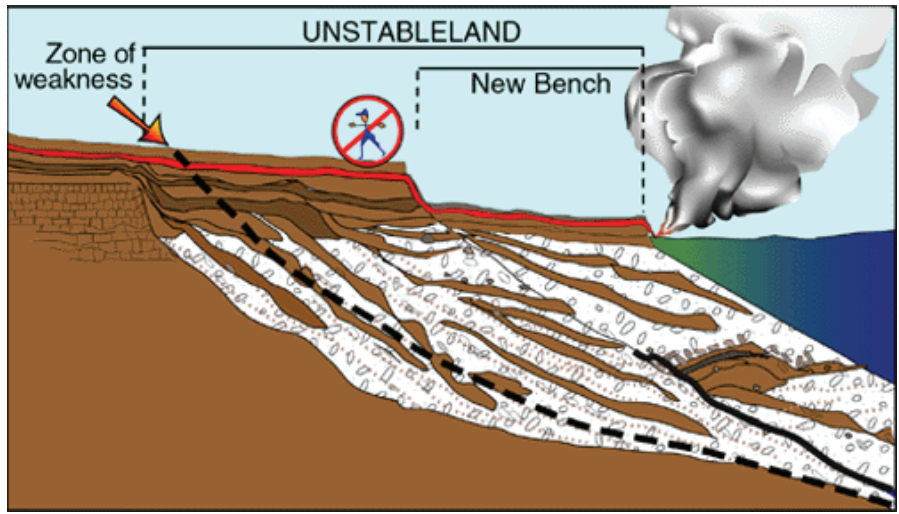

Fig. 4 Example of coastal section [2].

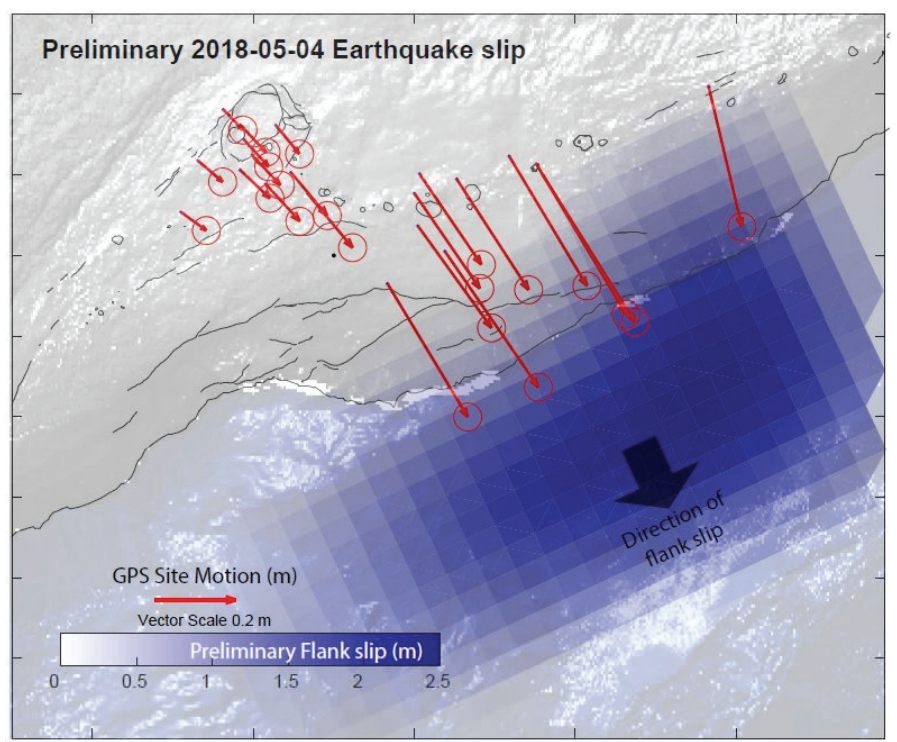

Fig. 5 After 6.9 earthquake (in May 2018) the southern coast of Hawaii shifted towards the ocean by about 2 feet, as shown here by GPS measurements.

Source: Hawaii Volcano Observatory. Seismo Blog. Berkeley Seismology Lab.

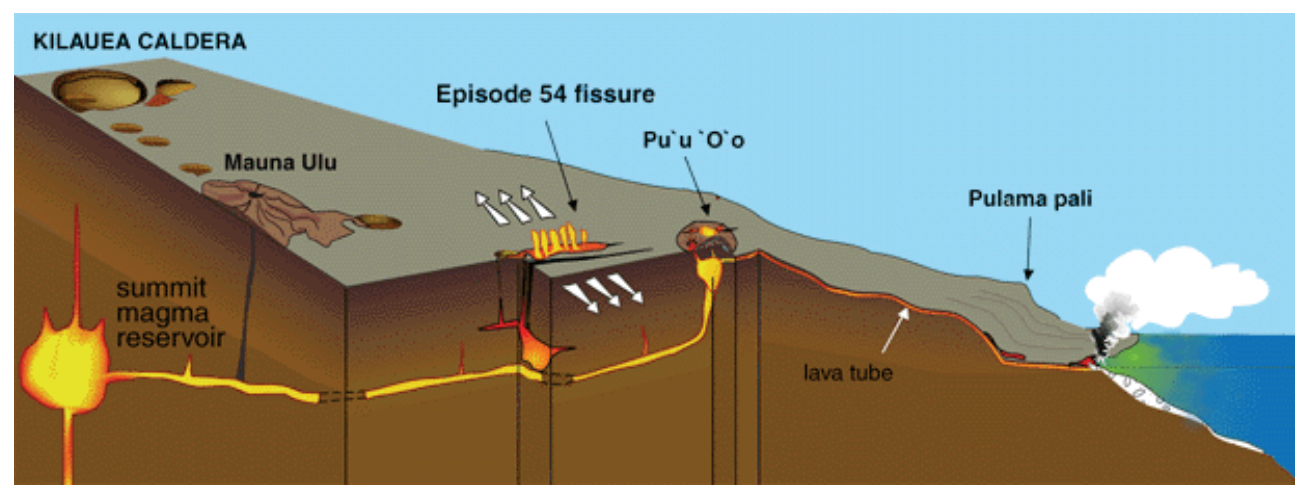

Fig. 6 Section of magma channel and natural lava tube formed by running out lava.

volcano crater, which is much higher than $\mathrm{Pu}$ 'u 'O'o. High magma pressure promotes new and reappearance of old fissures. Therefore, the number of them increased to 20. Fig. 7 shows an active fissure length almost 500 meters. The emergence of new cracks and activation of old ones can lead to a pressure drop in the incoming magma, which in turn can cause a sudden decrease in the magma level in the crater (for 
example, of Kilauea) and the occurrence of negative pressure between the volcano plug dome and magma level. This can subsequently lead to part of the caldera breaking off and falling into the crater.

In fact, the whole system of an erupting volcano and fissures through which lava pours out can be considered a system of interconnected vessels filled with heavy and hot liquid, where this liquid can also affect the vessels themselves. Magma coming up on the surface moves downward under the effect of gravity, and the top layer of lava quickly drops in temperature as it comes into contact with air, which causes its viscosity to increase. Therefore, as the lava moves, so-called lava tubes are formed (Fig. 8). Magma moves speedily along them without significant heat loss $\left(\sim 0.6{ }^{\circ} \mathrm{C}\right.$ per kilometer $)$ [2]. This process occurs while the accompanying gases and heat are released out as they pass along the existing wells of the lava tube.

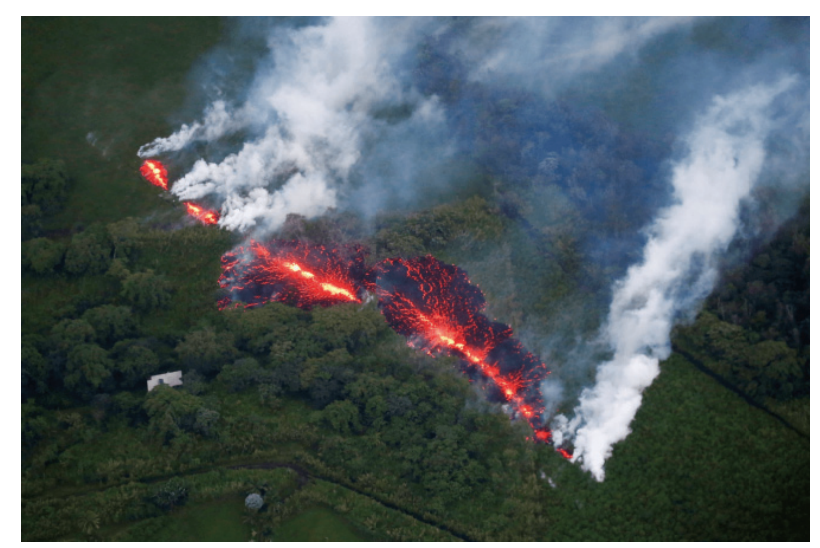

Fig. 7 Formed fissure.

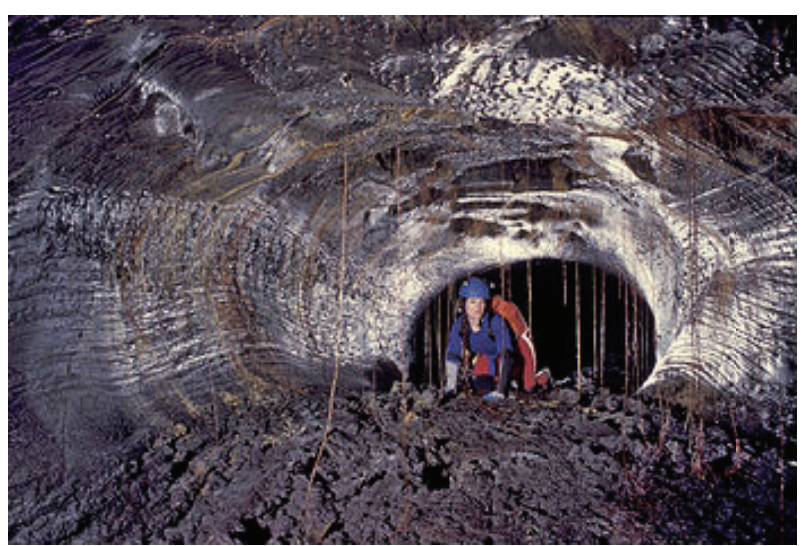

Fig. 8 Natural lava tube.
However, most of the lava does not come out from the lava tubes, but erupts through the crater onto the volcano slopes; see Fig. 2.

\section{Control of Lava Flows}

To control the lava flow, it is necessary to limit the release of magma to the Earth's surface, which requires conditions that make it possible to control the level of magma in the crater $[6,7]$. The method for controlling and reducing the magma level in the crater is given below. After completion of the active phase of eruption, the magma level stops at a certain equilibrium level. This is the level which is fixed in the volcanic magma lake; see Fig. 9.

Step 1. Let us lay a base lava tube with a diameter of $D_{\mathrm{o}}$ (for example, 4 meters) from a point at the foot of the volcano $\mathrm{T}_{0}$ (target level $\mathrm{Lg}$ ) to the ocean at point $T_{s}$ (lava drain); see Fig. 10. The difference in heights of the points $T_{o}$ and $T_{s}$ represents the vertical drop required for the lava flow. To ensure good conditions for lava flow under the effect of gravity, the tube shall be installed with a constant inclination. It is clear that these points are conditional, and they can be assigned depending on the terrain relief, properties of the magma, characteristics of the volcano, and other parameters.

Step 2. At the second step, we will drill a well for the auxiliary tube slightly above the existing magma level in the crater (for example, by 5 meters); see Fig. 11. We will insert a section of the auxiliary lava tube into the drilled well and at the same time lay a second auxiliary tube to drain lava and transfer it to the base tube at the point To. A disperser Ds ${ }^{*}$ will be installed at the exit point of the auxiliary tube. It will ensure raise of magma from the volcano crater [6].

After activating the disperser and pumping magma from the volcano to a level below the initial one (for example, by $30 \mathrm{~m}$ ), the next auxiliary well is drilled on 30 meters lower the previous one (Fig. 12). The figure shows the decrease in magma level in the volcano

\footnotetext{
${ }^{*}$ Russian patent has been obtained.
} 


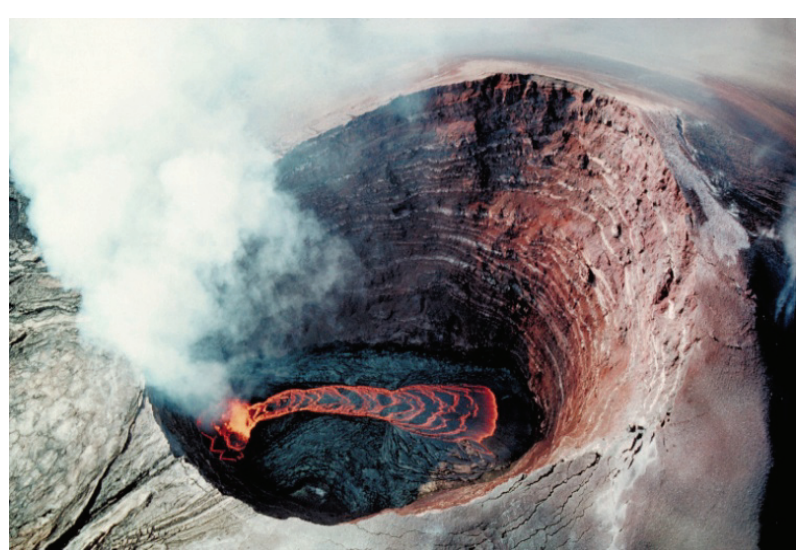

Fig. 9 The Pu'u 'O'o volcano crater after eruption.

crater and the second auxiliary tube.

Magma is pumped from the crater to the target level in a similar way. The end structure is shown in Fig. 13.

Thus, when magma achieves the resulted Lg level, it will be drained into the ocean via the auxiliary lava tubes. Alongside magma will also decrease to the same level in all other places where it gushes out-in fissures and craters connected with this crater by the common magma chamber. Decrease of magma level (for example, by $500 \mathrm{~m}$ ) will allow all the land located above to cool down and "set". These effects will drastically limit the potential of island destruction and make it possible to modify the relief in accordance with the plan by discharging lava into the ocean at a given place, filling gorges, etc.

Discharge of lava into the ocean has side effects, such as toxic gases and acid mist formed by tiny hard fragments of glass melt. These effects can be minimized by dumping lava not over the ocean, but directly into the ocean at a predetermined depth (see Fig. 14). For this purpose, it is necessary to lay a lava tube directly into the water deep with the installation of a special "bell", which will hold a certain amount of gas at the output end. This is done to prevent water from entering the lava tube by using the pressure of the fumarole gas in the tube, and the steam formed when the hot lava comes into contact with water.

According to this structural option, the lava flows into the ocean, while the gases escape around the edges of the dome and rise through the layer of seawater. This allows them to be significantly neutralized. The side walls of the lower part of the dome are perforated, with the larger diameter of the holes approaching the edge of the dome. The lower edge

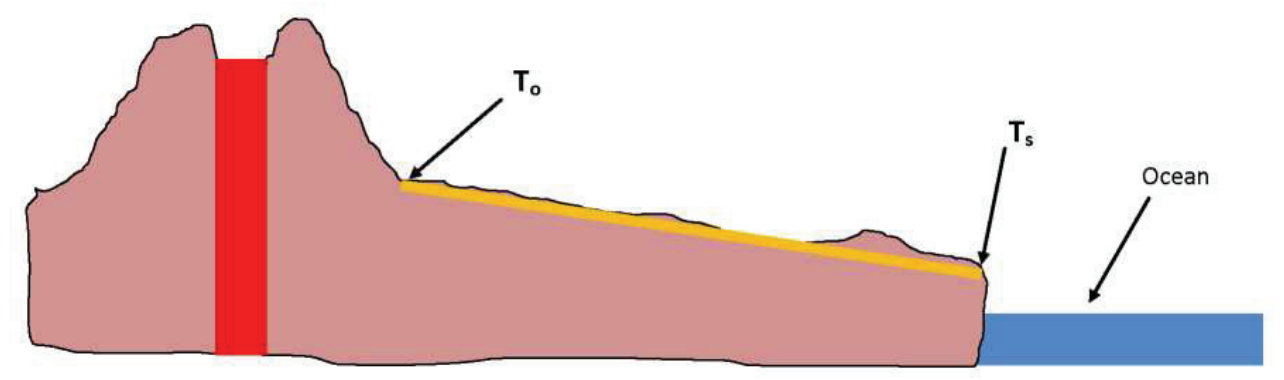

Fig. 10 Step 1.

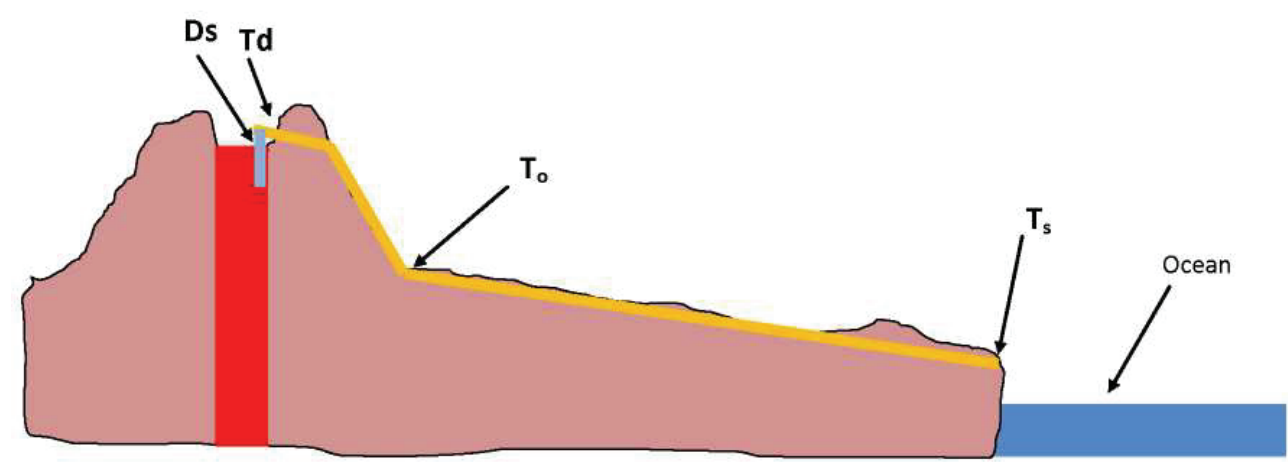

Fig. 11 Step 2-1. 


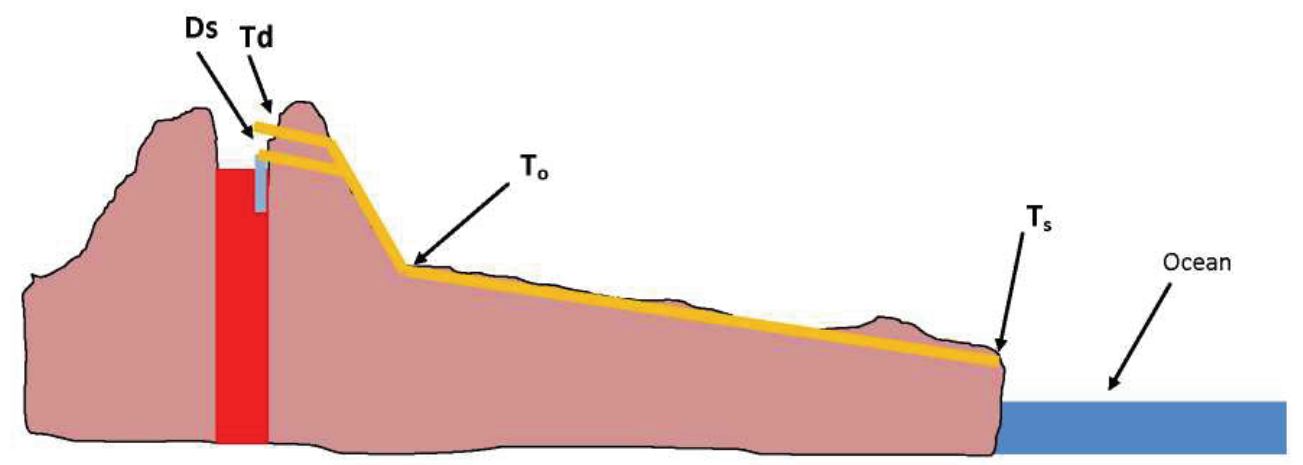

Fig. 12 Step 2-2.

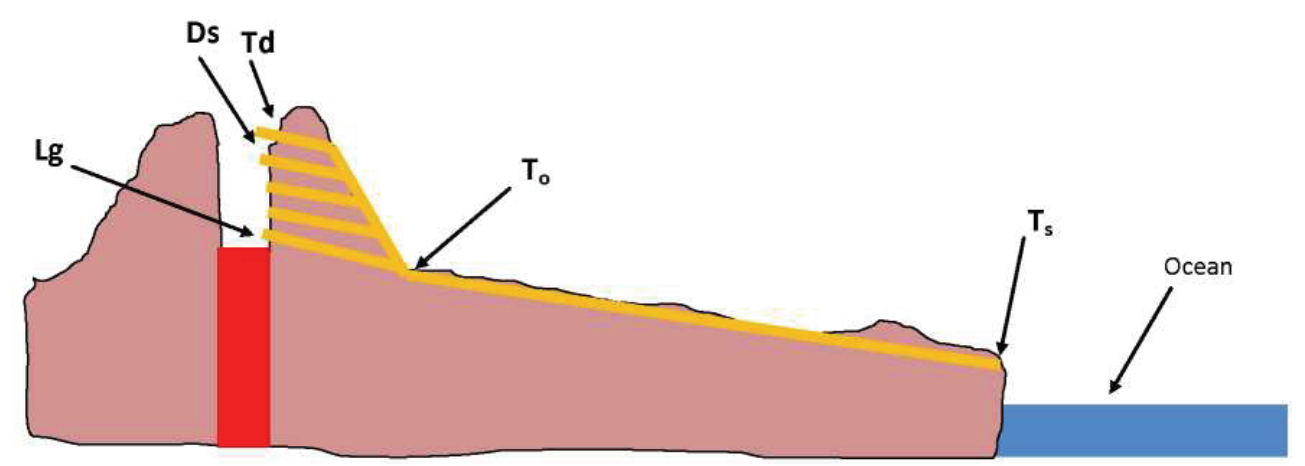

Fig. 13 Final variant.

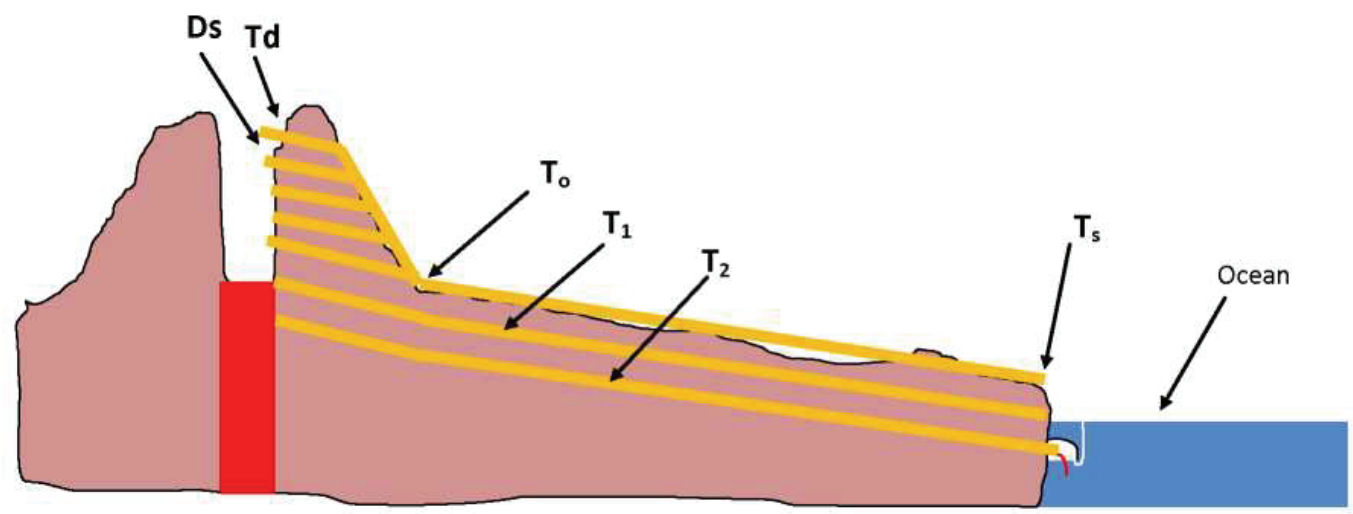

Fig. 14 Lava discharge into ocean.

of the dome has the form of teeth, which are aimed to split large gas bubbles into smaller ones.

\section{Artificial Lava Tube}

The lava tube is made of a refractory material, has thermal insulation and heating. It is installed with a constant angle of inclination, to ensure the magma downward moves towards the ocean under the effect of gravity. Thermal insulation is necessary to reduce heat loss as it drastically increases the viscosity of the melted material and decreases its fluidity. There are two options for heating the magma: using electricity or by gas mixture. An example of gas heating using electricity is given below in Figs. 15 and 16 (for example, it can be implemented as a heating wire simply wound on a tube with some pitch or laid on the bottom outside the tube).

In the second option for gas heating, a separated cavity in the lower part of the tube is used (combustion chamber). This is designed for burning the gas mixture. The heated gas is inserted into the lava flow through multiple injectors. Injectors are located 


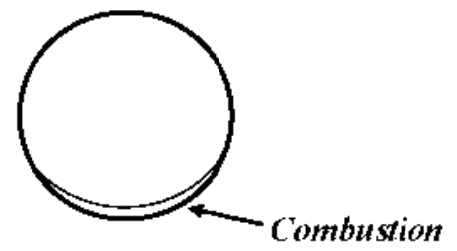

Fig. 15 Tube section with heating by gas mixture.

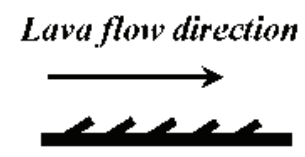

Fig. 16 Enlarged fragment of inner part of tube with injectors.

on the lower side of the inner surface of the tube and are inclined at an angle (for example, of $45^{\circ}$ ) in the direction of lava movement, which creates a "gas cushion" for the lava and heats it, while reducing its viscosity and facilitating its acceleration.

In Fig. 17, the lava flowing through the tube is shown in red. The combustion chambers are shown in the lower part of the tube. The combustion chamber is separated from the tube that supplies the gas mixture by means of a one-way valve, which allows gas to enter the chamber while preventing any backflow. Combustion of the gas mixture produces heat, which raises the temperature of the lava. In open areas, open heating of the lava tube can be arranged using a burner flame, without combustion chambers.

These isolated combustion chambers can be arranged along the tube part. The tube is also divided into sections $\mathrm{S}_{\mathrm{i}}$, with curtains installed at section borders. On the outside, the curtains are covered with graphite. They only raise in the direction of lava flow; arresters are provided to prevent the curtains from moving in the opposite direction. This movement stabilizes at the level perpendicular to the tube. The purpose of the curtains is to eliminate air movement along the tube from the bottom upwards, i.e. from the lava outflow point till the place of its inflow. This also reduces heat loss in the tube. The system of curtains blocking the air backflow creates the conditions in which the fumarole gases released from the lava increase the air pressure in the tube, and the air rushes down to the ocean along with the lava, thus accelerating the movement of the upper layers of magma.

In the lower end of each section $\mathrm{S}_{\mathrm{i}}$, a cone-shaped local drain is arranged at the bottom; see Fig. 17. These drains are equipped with autonomous electric high temperature heating (up to $1,400{ }^{\circ} \mathrm{C}$ ). They are needed at the very end of lava discharge, when its volume drops and the lava tube closes. At the end of lava discharge, the drain heating system is turned on. At the same time, the lava residues flow out from each section, opening the gas injectors.

At the point where magma enters the lava tube from the volcano crater, the metal layer is cut along the circumference at regular intervals (for example, 2 meters) on the outer side of the tube to reduce its diameter. The purpose of this is to preserve the tube during magma explosions in the volcano crater and destruction of the crater's inner edges. The weakened end of the tube, which goes into the crater, will break off, while the main tube will remain in working condition. To reduce the cost of construction, the lava tube can be made of refractory blocks with external insulation, except for the start and end points.

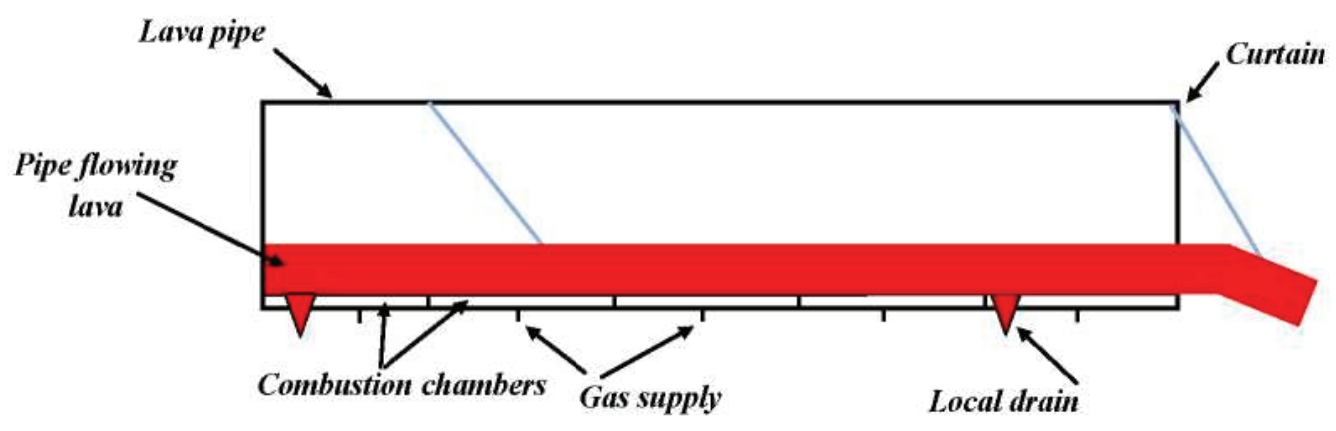

Fig. 17 Tube part, section $\mathbf{S}_{\mathrm{i}}$. 
Table 1 A summary of the proposals.

\begin{tabular}{|c|c|c|}
\hline No. & Presence of factor & Measures to reduce factor influence \\
\hline 1 & $\begin{array}{l}\text { Earthquake on South of the Island magnitude } \\
\text { of } 7.5 \text { is critical, as it provokes sliding of the } \\
\text { South-Eastern flank of the island to the ocean. }\end{array}$ & $\begin{array}{l}\text { Not preventable. The forecast, accounting for seismic zones while building } \\
\text { safer structures, as well as development of preventive measures. }\end{array}$ \\
\hline 2 & $\begin{array}{l}\text { Volcano eruption. Kilauea Volcano is } \\
\text { located on the slope of the larger volcano } \\
\text { Mauna Loa. The eruption of Kilauea volcano } \\
\text { results in the "softening" of the soil around } \\
\text { the crater and facilitates its sliding down the } \\
\text { slope towards the ocean. }\end{array}$ & $\begin{array}{l}\text { The forecast, development of preventive measures and planned modification of } \\
\text { the landscape around the volcano. Creation of a lava flow control system. } \\
\text { Drilling and laying of artificial lava tubes below the intersection line of the } \\
\text { slopes of Mauna Loa and Kilauea is possible. This will allow during the } \\
\text { eruption period to divert a significant part of the magma through lava pipes into } \\
\text { the ocean and significantly reduce the likelihood of the volcano sliding down. }\end{array}$ \\
\hline 3 & $\begin{array}{l}\text { Magma flows that penetrate extensively from } \\
\text { the crater into the island soil and do not } \\
\text { reach the surface can form a liquid } \\
\text { underground layer. }\end{array}$ & $\begin{array}{l}\text { Lowering the magma level, as well as magma discharge by means of artificial } \\
\text { lava tubes will allow keeping the stiffness of the soil above the marked by pipe } \\
\text { level. So, the height of the Kilauea volcano is equal to } 1,250 \text { meters, and the } \\
\text { height of the Pu'u 'O'o volcano is nearly } 800 \text { meters. The lava discharge } \\
\text { system will make it possible to decrease the magma level by approximately } 500 \\
\text { meters. This will prevent magma to reduce the soil stiffness at the level of these } \\
500 \text { meters on this part of the island. If independent small magma traps form } \\
\text { somewhere, they will cool by themselves. }\end{array}$ \\
\hline 4 & $\begin{array}{l}\text { Precipitation increases the weight of the } \\
\text { island and erodes the soil. Entering into the } \\
\text { depths, precipitation leads to explosions and } \\
\text { a sharp increase in internal pressure applied } \\
\text { to the soil, widening cracks and fractures. } \\
\text { This increases the risk of landslides. } \\
\end{array}$ & Arrangement of the drainage system, at least in the southern flank of the island. \\
\hline 5 & $\begin{array}{l}\text { Growth of mass of the above-water part of } \\
\text { the island to a critical value. }\end{array}$ & $\begin{array}{l}\text { Growth of mass in critical areas of the island can be partially limited by lava } \\
\text { discharge into the ocean or in pre-allocated places. Open engineering work on } \\
\text { soil transfer (including directional explosions, for example, from a drone) and } \\
\text { remote performance of overburden operations. }\end{array}$ \\
\hline 6 & $\begin{array}{l}\text { The island aquifers erode the soil and } \\
\text { weaken mechanical interaction between } \\
\text { different parts of the soil, which leads to an } \\
\text { increase in stress, since these parts are } \\
\text { adjacent to areas heated by magma. }\end{array}$ & $\begin{array}{l}\text { Construction of a water drainage system and transfer of the wells of the thermal } \\
\text { power plant to the northern part of the island. Injection of water into wells for } \\
\text { the production of superheated steam causes additional mechanical stresses that } \\
\text { facilitate fracture of cracks. }\end{array}$ \\
\hline 7 & \begin{tabular}{|l|} 
Erosion (washing away) of the island \\
above-water part by sea currents that can \\
easily roll over fragments of cooled lava and \\
significantly change the underwater \\
landscape of the island.
\end{tabular} & $\begin{array}{l}\text { Possibility of lava casting of three-dimensional objects to submerge on the } \\
\text { underwater slope of the volcano. }\end{array}$ \\
\hline
\end{tabular}

The lava coming from the crater can be used to cast products that will strengthen the underwater slope of the volcano, similar to dams that are installed on sea shores to protect them from eroding.

Let us consider the most important factors affecting the formation process of landslides and the proposed actions to minimize their impact.

Table 1 identifies the most important factors influencing the process of the formation of the landslides and the proposed actions to minimize their impact.

It is necessary to minimize the impact of all negative factors of the formation process of potential landslides. All these factors are already present on the island, and though each of them individually does not constitute a serious threat, their simultaneous effect can lead to a catastrophe. The most dangerous factor is a prolonged large magnitude earthquake [5].

\section{Conclusion}

The proposed method of controlling the lava flow and active influence on the slopes of the island make it possible to:

- Mitigate the negative effects of lava flows on the environment.

- Reduce uncontrolled growth of the volcano mass, 
as well as structure the landscape.

- Decrease the magma level in the crater and strengthen the higher layers of the volcano soil.

- Structure the landscape of the underwater part and strengthen the volcano underwater slopes (for example, to drain magma to the Eastern part of Hilina slump), as well as prevent coastline erosion.

The proposed method prevents occurrence of an uncontrolled huge landslide in the South-East flank of Hawaii Island, which could very well result from eruption of Kilauea and simultaneous multiple earthquakes above magnitude 7.5 (this is not something improbable). This landslide can reach a gigantic volume and lead to a catastrophic tsunami, which could cause estimated hundreds of billions of dollars in material damage to the entire West Coast of US, as well as destroy coastal cities, and take many lives. At present, no one can say when this huge landslide occurs, since this depends on many factors. But one can say with certainty that it will happen in the future. However, we must take steps to reduce its potential consequences!

\section{Reference}

[1] Neal, C. A., and Lockwood, J. P., eds. 2003. Geologic
Map of the Summit Region of Kilauea Volcano. Hawaii: Geologic Investigations, Series I-2759. U.S. Department of the Interior, U.S. Geological Survey.

[2] Merguerian, C., and Okulewicz, S. 2007. "Geology of Hawaii. Summer Session Two.” In Field Trip Guidebook.

[3] Moore, J. G., and Normark, W. R. 1994. "Giant Hawaiian Landslides." US Geological Survey, Menlo Park, California 94025, Robin T. Holcomb, US Geological Survey, University of Washington, Seattle, Washington 98195. Annual Reviews Inc. 1994. Provided by the NASA Astrophysics Data System, Annual Reviews Earth Planet. Sci. 22: 119-44.

[4] Schiffman, P., Watters, R. J., Thompson, N., and Walton, A. W. 2006. "Hyaloclastites and the Slope Stability of Hawaiian Volcanoes: Insights from the Hawaiian Scientific Drilling Project's 3-km Drill Core.” Journal of Volcanology and Geothermal Research 151 (1-3): 217-28.

[5] Smith, J. R., Malahoff, A., and Shor, A. N. 1999. "Submarine Geology of the Hilina Slump and Morpho-Structural Evolution of Kilauea Volcano, Hawaii." Journal of Volcanology and Geothermal Research 94 (1-4): 59-88.

[6] Bodyakin, V., and Kulmagambetov, A. 2018. "The Concept of Lava Flow Controlled Use as a Source of Energy and Materials." Journal of Energy and Power Engineering 12 (3): 140-9.

[7] Bodyakin, B., and Kulmagambetov, A. O. 2015. “возможности управления потоками лавы.” Химия $u$ Жизнь 7: 46-9. 